\title{
Assessment and the Psychological Aspects for Septorhinoplasty
}

\author{
${ }^{1}$ Catherine Rennie, ${ }^{2}$ Hesham Saleh
}

\begin{abstract}
In this article the authors discuss the assessment of patients undergoing septorhinoplasty emphasing the importance of psychological assessement in the preoperative work up. Patients motivations, anxieties and expectations are reviewed, key points to help identify problem patients are highlighted and specific questions to identfy those that may be suffering BDD are recommended. Facial proportions and the ideal angles of the facial esthetic triangle are described. A framework is presented to enable systematic analysis and examination of the face and nose to promote appropriate patient selection and facilitate surgical planning.
\end{abstract}

Keywords: Body dysmorphia, Psychology, Rhinoloplasty, Rhinoplasty assessment

How to cite this article: Rennie $\mathrm{C}$, Saleh $\mathrm{H}$. Assessment and the Psychological Aspects for Septorhinoplasty. Int J Head Neck Surg 2018;9(1):38-45.

\section{Source of support: Nil}

Conflict of interest: None

\section{INTRODUCTION}

Septorhinoplasty remains one of the most technically challenging procedures in facial plastic surgery. It is among the most popular cosmetic procedures performed worldwide. The rise in the "selfie" culture has led more people to seek surgery to create the perfect online portrait; hence, the number of septorhinoplasties is increasing year on year. Surgeons must apply careful consideration to their patient selection as well as to the esthetic and functional analysis of the nose in order to achieve the best outcomes for their patients. Understanding the psychological aspects of septorhinoplasty is of fundamental importance to the surgeon. Successful surgery requires realistic patient expectations with achievable goals and it is important to recognize those

${ }^{1}$ Consultant and Surgeon, ${ }^{2}$ Consultant Rhinologist Surgeon and Honorary Senior Lecturer

${ }^{1,2}$ Department of Otolaryngology, Charing Cross Hospital Imperial College Healthcare NHS Trust, London, UK

Corresponding Author: Catherine Rennie, Consultant and Surgeon, Department of Otolaryngology, Charing Cross Hospital, Imperial College Healthcare NHS Trust, London, UK, e-mail: rennie.catherine@gmail.com patients who may have an unfavorable postoperative course regardless of objective outcomes.

In this article, we propose a systematic approach to the assessment of patients for septorhinoplasty that will enable appropriate patient selection and facilitate surgical planning. Assessment should include:

- Consideration of the patients' motivations, anxieties, and expectations,

- Analysis of the face,

- Analysis of the nose,

- Examination, and

- Photography.

\section{Patients' Motivations, Anxieties, and Expectations}

At the first consultation, a clear history of the patients' complaints and symptoms must be taken and documented. It is crucial to identify any structural, congenital, traumatic, cosmetic, and/or functional issues. Any past history of nasal surgery, sinonasal disease, diabetes, psychopathology, anticoagulant medication, smoking, or cocaine use should be elicited as they could have significant implications for future surgery.

It is important to understand the patients' motivations, anxieties, and expectations. What makes the patient want to undergo surgery with its associated inconvenience and risk often for a seemingly minor defect? Many people have nasal abnormalities but only a small number choose to have corrective surgery. A number of rhinoplasty patients relate their focus on their nose back to puberty; they describe becoming increasingly dissatisfied over time when looking at their daily reflection in the mirror. ${ }^{1}$ Since the rise in the "selfie" culture, patients have become more self-aware of their appearance. Increasingly, we are seeing patients who state that they do not mind their frontal face in photos, but the side profiles and other angles used in selfies trigger worries in their appearance and incite them to do something about it, often caused by a public photograph. When compared with patients seeking other cosmetic procedures, those seeking rhinoplasty show higher levels of dissatisfaction in their personal appearance. ${ }^{2,3}$ Most patients seeking rhinoplasty are motivated by a desire to change or having seen favorable outcomes in others. ${ }^{4}$ It is not usually the severity of their deformity that leads patients to surgery, ${ }^{5}$ 
but more commonly their perceived difference from the normal in their social environment. The timing for rhinoplasty often coincides with a loss in self-esteem. Studies have shown that rhinoplasty surgery results in a positive effect on the patients' body image, which is still present at 2 years following the procedure. ${ }^{6}$

Recognizing potentially problematic patients is one of the greatest challenges for the rhinoplasty surgeon, as these patients are unlikely to be satisfied with surgical results. Identifying patients' body image concerns may raise suspicion of a high-risk patient. A number of personality attributes that are considered unfavorable for cosmetic surgery have been described in the literature. Examples commonly referred to are patients who are unreasonably demanding or overly flattering, patients that insist on secrecy, the so-called surgiholic, as well as obsessive, perfectionist, and impolite patients. The simplified acronym SIMON (single, immature, male, overly expectant/obsessive, narcissistic) describes a high-risk patient, whereas the acronym SYLVIA (secure, young, listens, verbal, intelligent, attractive) describes an ideal patient. ${ }^{7-9}$ While these acronyms are recognized as being overly simplified, they can still provide a guide to the surgical team.

There are a number of red flag signs that the surgeon should be aware of as these suggest a high-risk patient or one suffering from body dysmorphic disorder (BDD) (Table 1). In such cases a psychologist's opinion should be sought prior to considering surgery and obtaining a second surgeon's opinion would be wise before contemplating surgery.

The BDD describes an altered perception of one's own appearance resulting in distress. It is a subjective feeling of ugliness or physical defect which the patient believes is noticeable to others, although the appearance is within normal limits. ${ }^{10}$ Typically BDD starts in late adolescence and is chronic in nature, affecting men and women equally. Studies have shown that $33 \%$ of patients seeking rhinoplasty have moderate symptoms of BDD. However, this is much lower at only $2 \%$ of those seeking
Table 1: Red flags

Body image concerns that are difficult for others to see

Unrealistic expectations of treatment outcomes

Worrying about body image repeatedly throughout the day or for long periods

Use of camouflaging and cover-up strategies

Constant requests for reassurance

Mirror checking, or avoidance of mirrors

Avoidance of social situations

General reduction in quality of life (e.g., no longer socializing)

Disruption in daily activity

Patient presents with numerous photos (of self or of models/ celebrities)

Patient presents with detailed ideas of how to improve appearance

Patient has other areas of body image concern

Patient reports multiple previous "ineffective" consultations or treatments

Overly familiar patients

rhinoplasty for medical reasons, whereas the figure was much higher at $43 \%$ in those seeking rhinoplasty for purely cosmetic reasons. ${ }^{11,12}$

Three questions based on the Diagnostic and Statistical Manual of Mental Disorders, 4th Edition criteria have been developed to help surgeons screen for BDD:

- Are you worried about your appearance in any way?

- Does this concern or preoccupy you? That is, do you think about it a lot and wish you could worry about it less?

- What effect has this preoccupation with your appearance had on your life ${ }^{13,14}$

A number of other questionnaires have been developed that can help identify patients with unrealistic expectations and those with suspected BDD (Table 2). However, to date, there is no consensus on a specific rhinoplasty questionnaire.

Preoperative psychological assessment is essential in all patients where BDD is suspected. ${ }^{10}$ If BDD and other psychopathology are ruled out, the patient can then be counseled regarding surgery; however, if the surgeon still has significant concerns it may be necessary to get a second opinion.

Table 2: General and specific questionnaire

\begin{tabular}{|c|c|c|}
\hline \multicolumn{2}{|c|}{ Specific } & \multirow[b]{2}{*}{ General } \\
\hline Rhinoplasty & Cosmetic surgery & \\
\hline Rhinoplasty outcome evaluation (ROE) ${ }^{15-20}$ & Cosmetic procedures screening scale ${ }^{21}$ & Derriford appearance scale (DAS59) $)^{18,22,23}$ \\
\hline $\begin{array}{l}\text { Expectations of esthetic rhinoplasty scale } \\
(\text { EARS })^{24}\end{array}$ & $\begin{array}{l}\text { Body dysmorphic disorder questionnaire } \\
(\mathrm{BDDQ})^{25}\end{array}$ & Brief fear of negative evaluation scale ${ }^{25}$ \\
\hline $\begin{array}{l}\text { The Utrecht questionnaire for outcome } \\
\text { assessment in esthetic rhinoplasty }{ }^{26}\end{array}$ & $\begin{array}{l}\text { Yale-Brown obsessive scale modified for } \\
\text { BDD }^{22}\end{array}$ & Hospital anxiety and depression scale ${ }^{26}$ \\
\hline \multirow[t]{3}{*}{ The RHINO scale 27} & Dysmorphic concern questionnaire ${ }^{28}$ & Glasgow benefit inventory ${ }^{23,29-33}$ \\
\hline & FACE-Q ${ }^{20,34-39}$ & $\begin{array}{l}\text { Neuroticism-extraversion-openness five- } \\
\text { factor inventory (NEO-FFI) }\end{array}$ \\
\hline & $\begin{array}{l}\text { Body dysmorphic disorder examination- } \\
\text { self report (BDDE-SR) }\end{array}$ & Symptom checklist-90-revised (SCL-90-R) ${ }^{40}$ \\
\hline
\end{tabular}




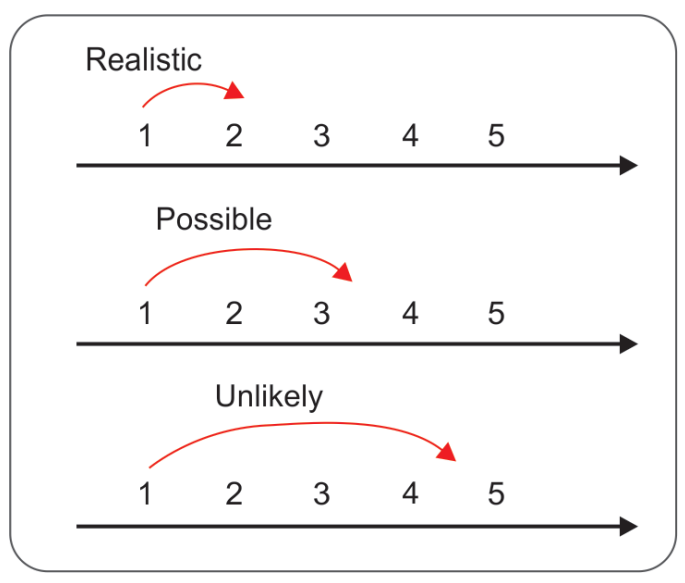

Fig. 1: Rhinoplasty improvement scale used by the senior author

Determining preoperative expectations is crucial as poor outcomes are more frequently due to emotional dissatisfaction rather than technical failure. ${ }^{42,43}$ The use of the rhinoplasty improvement scale is helpful in counseling patients about realistic postsurgical expectations; moving up one point on the scale is realistic but anything more than this is unlikely (Fig. 1).

\section{Analysis of the Face}

It is important to consider the face as a whole and not only the nose in isolation. Leonardo da Vinci first described the ideal measurements and angles of an attractive face ${ }^{44,45}$; this concept has since been extended by for use in facial plastic surgery by Albrecht Duerer ${ }^{46}$ and Powell and Humphrey. ${ }^{47}$

Facial symmetry has long been seen as an important marker of facial beauty, although minor asymmetry may also be associated with the perception of beauty. ${ }^{48}$ Patients may be unaware of minor facial asymmetries prior to surgery; it is therefore, important to discuss these with the patient and clearly document them as it could lead to dissatisfaction and misunderstanding in the postoperative period. Although a rhinoplasty on an asymmetrical face can lead to dissatisfaction postsurgery, correcting an asymmetrical nose which causes the illusion of facial asymmetry can lead to improved facial symmetry without the need for any other surgical procedure. ${ }^{49,50}$

Symmetry is assessed using midline facial landmarks; a line running through the mid-philtrum of the upper lip, the midpoint of the glabella, and the midpoint of the chin allows assessment of symmetry.

Analysis of facial proportions is performed using the "rule of thirds" and the "rule of fifths" to assess the face from a frontal view (Fig. 2). ${ }^{45}$ Horizontal facial thirds should be approximately equal, the landmarks defining each third are the trichion to glabella, glabella to subnasale, and the subnasale to soft tissue menton. The rule of fifths describes the ideal transverse propor-

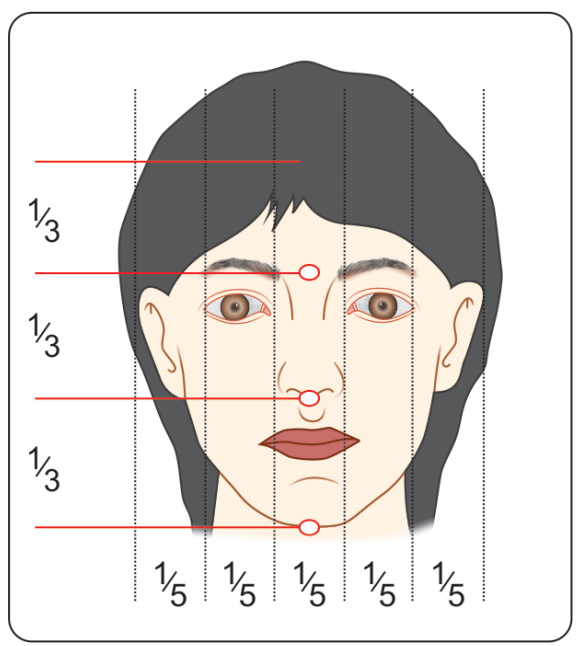

Fig. 2: The concept of dividing the symmetric face into thirds and fifths

tions of the face vertically divided into equal fifths, each fifth is approximately equal to the width of one eye; the alar base is equal to the intercanthal distance. The nose ideally occupies one-third of the length of the face and one-fifth of its width. It is important to also consider the protrusion of the chin as well as the fullness and position of the lip.

Powell and Humphrey ${ }^{47}$ described the ideal angles of the facial esthetic triangle (Fig. 3). The accepted dimensions of each of the facial angles are: Nasofrontal angle 115 to $135^{\circ}$; nasofacial angle 30 to $40^{\circ}$; nasomental angle 120 to $132^{\circ}$, and the mentocervical angle 80 to $95^{\circ}$. These angles and proportions provide a useful guide in planning procedures but do vary between ethnicities. Each rhinoplasty should respect the individuals' wishes, gender, and character. ${ }^{51}$

Finally the analysis of the face should include inspection of skin type utilizing the Fitzpatrick classification, which divides the skin type based on its color and its reaction to the first summer exposure. ${ }^{52}$ The surgeon should consider the skin wrinkles on both with and without expression. ${ }^{53}$

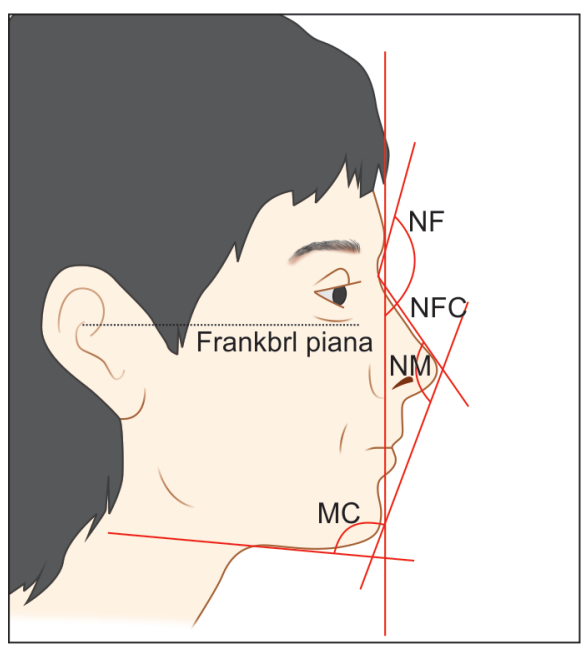

Fig. 3: Triangles of Powell and Humphrey ${ }^{47}$ 


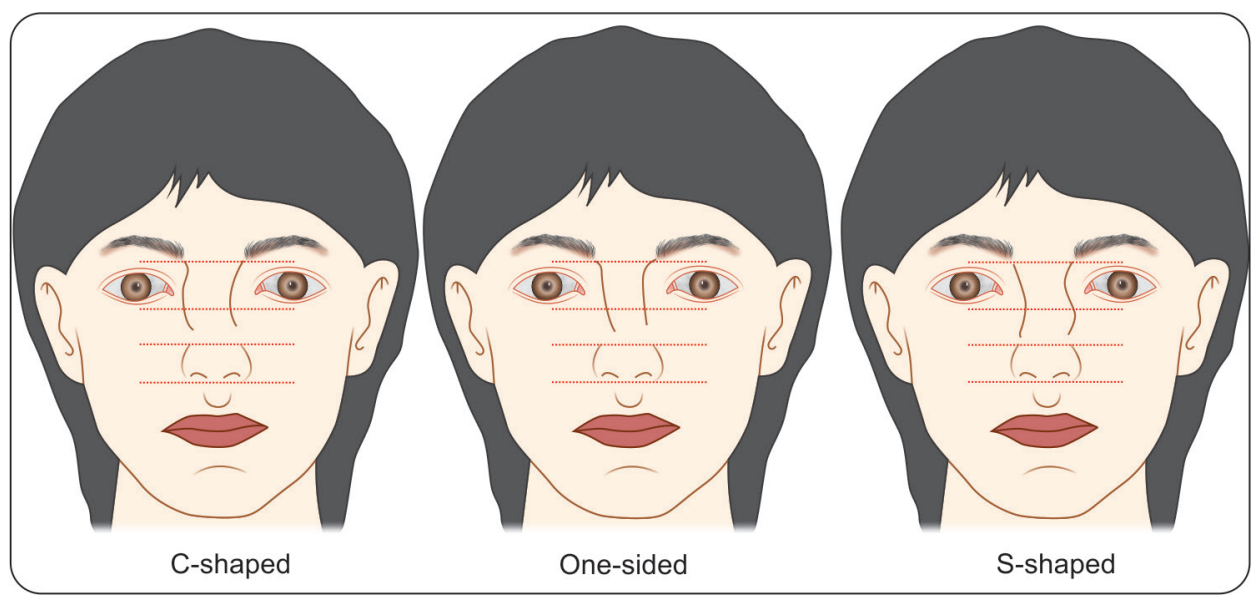

Fig. 4: Classifying classic nasal deviations using thirds

\section{Analysis of the Nose}

Analysis of the nose comprises of three areas: inspection of the external nose, inspection of the internal nose, and palpation.

\section{Inspection of the External Nose}

- Skin: Failure to assess its quality prior to surgery can significantly impact results. While subtle tip improvements may be more easily appreciable in thin skin, it remains more unforgiving, displaying minor irregularities more readily; by contrast refining and narrowing the nasal tip can be challenging in thick sebaceous skin.

- Deviations: The nose is divided into upper, middle, and lower thirds. The upper third corresponds to the bony vault, the middle third to the upper lateral cartilages and dorsal septum, and the lower third to the lower lateral cartilages, caudal septum, and alar base. Nasal deviations are commonly classified by one-sided shape, c-shaped, or s-shape (Fig. 4).

- Length of the nose: Nasal length is measured from the nasion to the tip, which is equal to the distance between the stomium and the menton. This can also be calculated mathematically as the distance from the nasal tip to the stomium multiplied by a constant of 1.6. Nasal length, NT = TS $\times 1.6$ (Fig. 5).

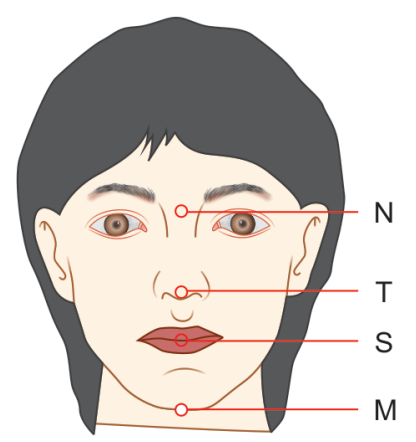

Nasal length $(\mathrm{N}-\mathrm{T})$

Stomium to menton (S-M)

$1.6 \times(\mathrm{T}-\mathrm{S})$

Fig. 5: Nasal length
- Tip projection: The anterior distance that the nasal tip protrudes in front of the face. Goode's ratio determines the ideal projection, where a line drawn from the alar-facial groove to the nasal tip measures 0.55 to 0.60 of the distance from the nasion to the nasal tip. A ratio less than this equates to an underprojected tip and greater than this corresponds to overprojection (Fig. 6).

- Lip-chin relationship: In profile the surface of the upper lip is typically $2 \mathrm{~mm}$ anterior to that of the lower lip. The anterior surface of the upper and lower lips rests on the nasomental line in an esthetic face (Fig. 7). ${ }^{54}$ A retrognathic chin lies posterior to this line, and a prognathic chin lies anterior. A retrognathic chin can give the illusion of an overprojected tip and the reverse applies to a prognathic chin. Genioplasty or chin implant procedures are therefore, often used in conjunction with rhinoplasty. ${ }^{55}$

- Dorsum: The dorsum is inspected from both frontal and lateral views. Following the brow-tip line (lateral esthetic lines) should reveal a smooth curvilinear line connecting the eyebrow superiorly to the nasal tip inferiorly (Fig. 8). Irregularities in this smooth curve highlight sources of nasal deformity. In the

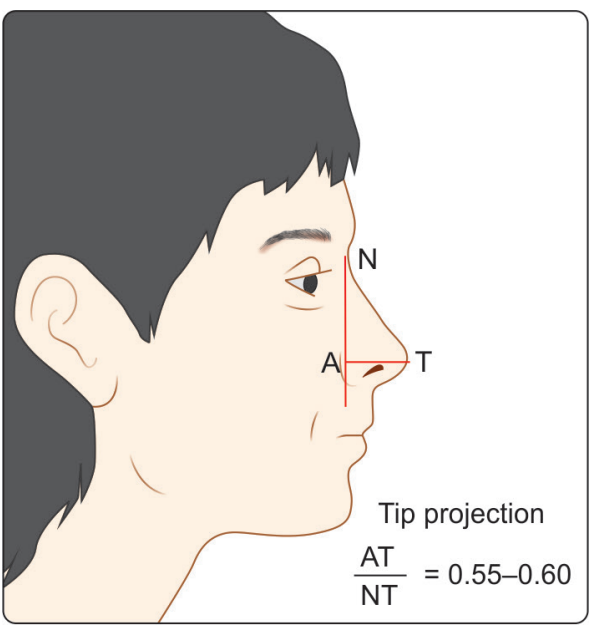

Fig. 6: Determining tip projection using Goode's ratio 


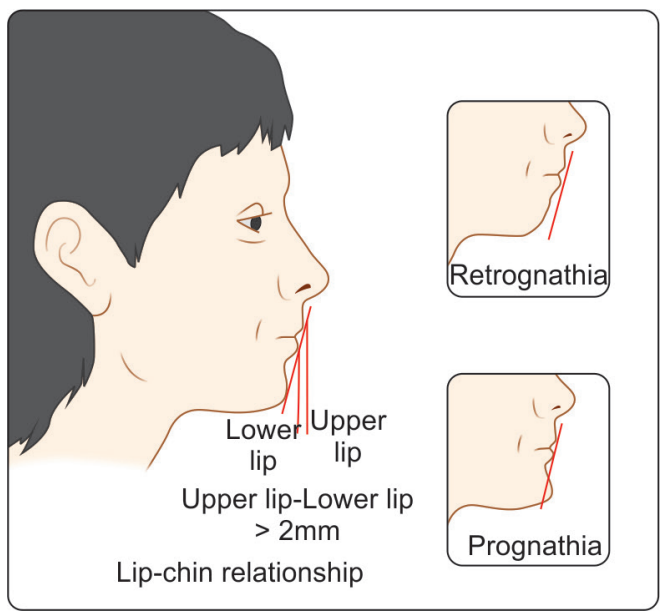

Fig. 7: Lip-chin relationship

lateral view, the height of the dorsum is assessed; the dorsum is a straight line in men and in women gently curves with a supratip break delineating the dorsum from the nasal tip. There are wide variations in nasal dorsum height and these are often characteristic of ethnicity.

- Tip configuration: There are four tip-defining points identified by light reflection (Fig. 8). These represent the domes, the supratip, and infratip. The tip is assessed for any asymmetry, bifidity, and rotation. The size and shape of the lower lateral cartilages and skin thickness are also inspected. Various tip configurations, such as normal, boxy, bifid, bulbous, and amorphous are related to these characteristics. Figure 9 depicts these commonly encountered tip appearances.

- Tip rotation: Describes the position of the tip along an arc with its radius centered on the nasolabial angle. The ideal dimension of the nasolabial angle in women is 95 to $105^{\circ}$ and in a man is 90 to $95^{\circ}$ (Fig. 10). ${ }^{56}$

- Columellar: Shows the relationship between the ala and the columella assessed in the lateral view. The amount of visible caudal septum is ideally limited to 3 to $5 \mathrm{~mm}$ (Fig. 10). This is the distance between two parallel lines drawn from the anteriormost and the posteriormost parts of the nasal vestibule. If the degree of columellar show is less than this, there may be columella retraction and if greater than this there may be either a hanging columella or abnormalities in the alar margins, such as notching or retraction.

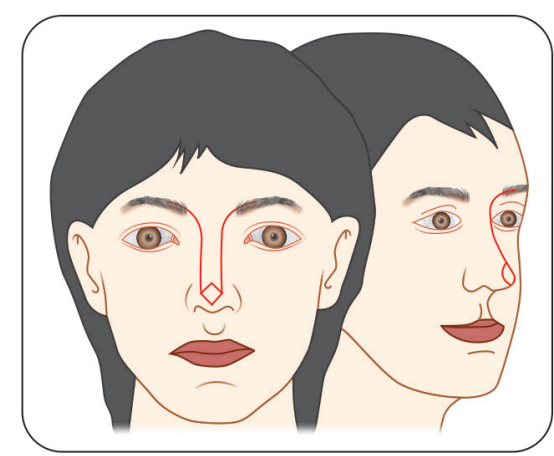

Fig. 8: Front and right oblique views showing the brow-tip line-note the four tip-defining points

- Basal view: The width of the alar base approximates to the intercanthal distance. The ratio of the width of the dorsum of the nose relative to the alar base should be equal to $80 \%$ (Fig. 2). From the basal view, the nose can also be divided into thirds. The upper third corresponds to the lobule and the lower two-thirds correspond to the columella. A line that transects the columella at the area of medial crural footplate diversion divides the base into two halves (Fig. 11). The overall basal view outline conforms to an isosceles triangle with pear-shaped nostrils lying at an angle of $45^{\circ}$ to the vertical. ${ }^{57}$ Multiple ethnic variations exist in alar base configuration.

\section{Inspection of the Internal Nose}

Anterior rhinoscopy and nasal endoscopy should be performed:

- Septum: Inspection for deviation, spurs, perforation, or the presence of a septal button.

- Lateral nasal wall and turbinates: Inspection for congestion, hypertrophy, and asymmetry.

- Internal nasal valve: This must be assessed during normal quiet respiration at rest, as exaggerated effortful breathing is likely to precipitate transient internal nasal valve collapse in the normal individual.

- A better maneuver than Cottle's is to place a JobsonHorne probe in the internal nasal valve to prevent the collapse of the upper lateral cartilage and detect its effect on inspiration.

- Alar collapse: Must be identified preoperatively, it is a measure of external nasal valve collapse. The external
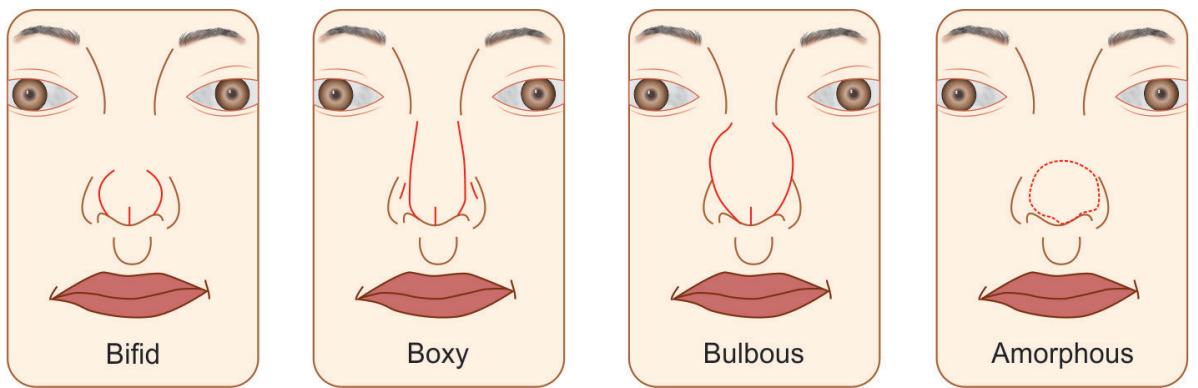

Fig. 9: Common nasal tip morphology 


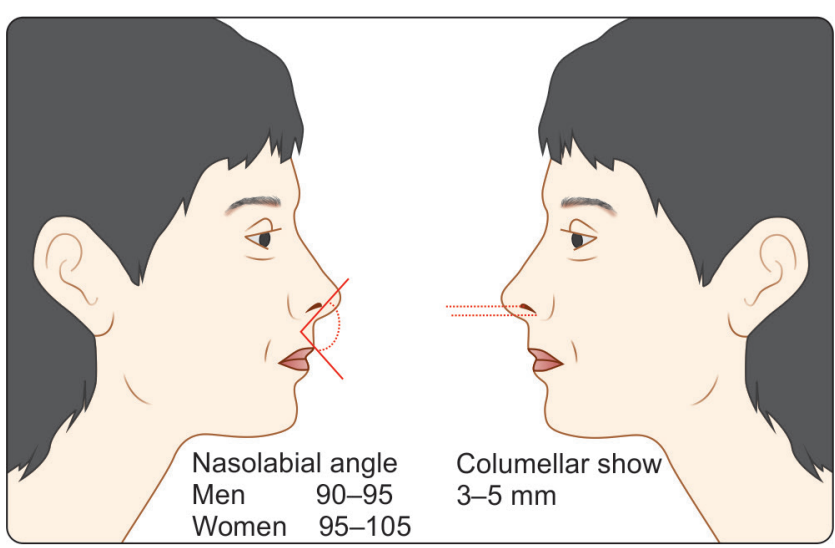

Fig. 10: Left-nasolabial angle in men and women. Rightnormal columellar show

nasal valve is not a true valve and is identified by the area bounded by alar cartilages, septum, and columella.

- Endoscopy to exclude polyps, purulent discharge, or residual adenoidal tissue.

\section{Palpation}

- Skin: Palpate for an assessment of skin texture and elasticity.

- Irregularities: Palpate for underlying irregularities that may be due to skin, soft tissue, cartilage, bone, or previous graft material.

- Tip recoil: This is an assessment of the strength of the lower third of the nose and provides a palpable measure of the degree of underlying tip support. ${ }^{58}$

- Alar cartridges: Palpate for thickness, strength, and shape.

- Spine and septum: Tip support, confirm presence and quantity of septal cartilage.

- Nasal bones: Assess the size, position, and presence of palpable steps.

\section{Functional Studies}

Nasal inspiratory peak flow, acoustic rhinometry, and rhinomanometry have all been used as objective tests of nasal function and to quantify surgical results. However, the correlation between objective and subjective sensation of nasal patency remains uncertain. ${ }^{59}$ As a result, studies of nasal function are not performed routinely in rhinoplasty assessment and are mainly confined to the research environment.

\section{Photograph Review}

Photography is essential for surgical planning; it enables an informed discussion with the patient, provides a

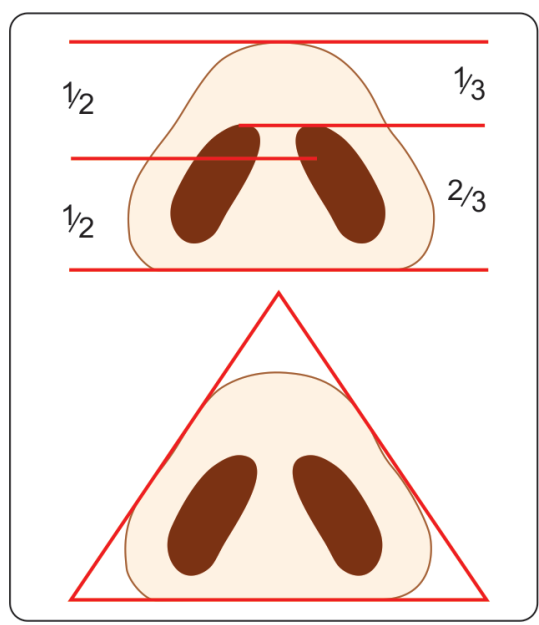

Fig. 11: Basal view

useful intraoperative reference, and allows comparison of pre- and postoperative results. In order to achieve reproducible photographs, a standard patient position is used where the Frankfurt plane is parallel to the floor; the Frankfurt plane is a line that runs from the cephalic tragus to lower orbital margin (Fig. 3). The standard photographic views obtained for rhinoplasty are frontal, left and right lateral, left and right oblique, and basal. Additional views, which can be of use, are the close-up frontal view, superior view, base-radix view, and the bird's eye view. ${ }^{60-62}$

\section{Computer Imaging}

Computer morphing of the preoperative photographs improves communication with patients, it can help manage expectations and is associated with higher patient satisfaction. ${ }^{63}$ It may also help identifying BDD by highlighting unrealistic expectations. ${ }^{64}$ More recently, 3D surface imaging and manipulation has been used in the assessment of rhinoplasty. Its role is yet to be explored further and compared with standard imaging. 65,66

However, it is important that the patient is aware that image manipulation does not guarantee a specific outcome, it is only a means of improved communication and understanding.

\section{CONCLUSION}

In this article, we have outlined a systematic framework for rhinoplasty assessment to enable appropriate patient selection and facilitate surgical planning. We have highlighted the importance of exploring patients' motivations, anxieties, and expectations, to allow early identification of potential problem patients. Following the systematic assessment and examination of the patient, the proposed surgery can be effectively planned and communicated with the patient. A clear surgical plan with each of the surgical steps can be drawn up and it is good practice to commit to a written plan. 


\section{REFERENCES}

1. Haraldsson PO. Psychosocial impact of cosmetic rhinoplasty. Aesthetic Plast Surg 1999 May;23(3):170-174.

2. Sperry S, Thompson JK, Sarwer DB, Cash TF. Cosmetic surgery reality TV viewership: relations with cosmetic surgery attitudes, body image, and disordered eating. Ann Plast Surg 2009 Jan;62(1):7-11.

3. Rankin M, Borah GL, Perry AW, Wey PD. Quality-of-life outcomes after cosmetic surgery. Plast Reconstr Surg 1998 Nov;102(6):2139-2145.

4. Shulman O, Westreich M, Shulman J. Motivation for rhinoplasty: changes in 5970 cases, in three groups, 1964 to 1997. Aesthetic Plast Surg 1998 Nov;22(6):420-424.

5. Napoleon A, Lewis CM. Psychological considerations in lipoplasty: the problematic or "special care" patient. Ann Plast Surg 1989 Nov;23(5):430-432.

6. Tasman AJ. Rhinoplasty - indications and techniques. GMS Curr Top Otorhinolaryngol Head Neck Surg 2007;6:Doc09.

7. Adamson PA, Chen T. The dangerous dozen--avoiding potential problem patients in cosmetic surgery. Facial Plast Surg Clin North Am 2008 May;16(2):195-202.

8. Rohrich RJ. Streamlining cosmetic surgery patient selectionjust say no! Plast Reconstr Surg 1999 Jul;104(1):220-221.

9. Tardy, ME Jr. Rhinoplasty: the art and the science. Philidelphia (PA): Saunders; 1997.

10. Jakubietz M, Jakubietz RJ, Kloss DF, Gruenert JJ. Body dysmorphic disorder: diagnosis and approach. Plast Reconstr Surg 2007 May;119(6):1924-1930.

11. Picavet VA, Prokopakis EP, Gabriels L, Jorissen M, Hellings PW. High prevalence of body dysmorphic disorder symptoms in patients seeking rhinoplasty. Plast Reconstr Surg 2011 Aug;128(2):509-517.

12. Joseph J, Randhawa P, Hannan SA, Long J, Goh S, O'Shea N, Saleh H, Hansen E, Veale D, Andrews P. Body dysmorphic disorder in patients undergoing septorhinoplasty surgery: should we be performing routine screening? Clin Otolaryngol 2017 Jun;42(3):508-513.

13. Phillips KA. Body dysmorphic disorder: recognizing and treating imagined ugliness. World Psychiatry 2004 Feb;3(1):12-17.

14. Palma P, Khodaei I, Tasman AJ. A guide to the assessment and analysis of the rhinoplasty patient. Facial Plast Surg 2011 Apr;27(2):146-159.

15. Alsarraf R. Outcomes research in facial plastic surgery: a review and new directions. Aesthetic Plast Surg 2000 May-Jun;24(3):192-197.

16. AlsarrafR,LarrabeeWF,AndersonS,MurakamiCS,JohnsonCM. Measuring cosmetic facial plastic surgery outcomes: a pilot study. Arch Facial Plast Surg 2001 Jul-Sep;3(3):198-201.

17. Picavet VA, Gabriels L, Grietens J, Jorissen M, Prokopakis EP, Hellings PW. Preoperative symptoms of body dysmorphic disorder determine postoperative satisfaction and quality of life in aesthetic rhinoplasty. Plast Reconstr Surg 2013 Apr;131(4):861-868.

18. Gunel C, Omurlu IK. The effect of rhinoplasty on psychosocial distress level and quality of life. Eur Arch Otorhinolaryngol 2015 Aug;272(8):1931-1935.

19. Lekakis G, Picavet VA, Gabriels L, Grietens J, Hellings PW. Body Dysmorphic Disorder in aesthetic rhinoplasty: validating a new screening tool. Laryngoscope 2016 Aug;126(8): 1739-1745.
20. Joseph AW, Ishii L, Joseph SS, Smith JI, Su P, Bater K, Byrne P, Boahene K, Papel I, Kontis T, et al. Prevalence of body dysmorphic disorder and surgeon diagnostic accuracy in facial plastic and oculoplastic surgery clinics. JAMA Facial Plast Surg 2017 Jul;19(4):269-274.

21. Veale D, Ellison N, Werner TG, Dodhia R, Serfaty MA, ClarkeA. Development of a cosmetic procedure screening questionnaire (COPS) for body dysmorphic disorder. J Plast Reconstr Aesthet Surg 2012 Apr;65(4):530-532.

22. Carr T, Moss T, Harris D. The DAS24: a short form of the Derriford Appearance Scale DAS59 to measure individual responses to living with problems of appearance. $\mathrm{Br} \mathrm{J}$ Health Psychol 2005 May;10(Pt 2):285-298.

23. Herruer JM, Prins JB, van Heerbeek N, Verhage-Damen G, Ingels $\mathrm{K}$. Does self-consciousness of appearance influence postoperative satisfaction in rhinoplasty? J Plast Reconstr Aesthet Surg 2018 Jan;71(1):79-84.

24. Naraghi M, Atari M. Development and Validation of the Expectations of Aesthetic Rhinoplasty Scale. Arch Plast Surg 2016 Jul;43(4):365-370.

25. Phillips, KA. The broken mirror: understanding and treating body dysmorphic disorder. Revised and Expanded Edition. New York: Oxford University Press; 2005.

26. Lohuis PJ, Hakim S, Duivesteijn W, Knobbe A, Tasman AJ. Benefits of a short, practical questionnaire to measure subjective perception of nasal appearance after aesthetic rhinoplasty. Plast Reconstr Surg 2013 Dec;132(6):913e-923e.

27. Lee MK, Most SP. A comprehensive quality-of-life instrument for aesthetic and functional rhinoplasty: the RHINO scale. Plast Reconstr Surg Glob Open 2016 Feb;4(2):e611.

28. Mancuso SG, Knoesen NP, Castle DJ. The dysmorphic concern questionnaire: a screening measure for body dysmorphic disorder. Aust N Z J Psychiatry 2010 Jun;44(6):535-542.

29. Robinson K, Gatehouse S, Browning GG. Measuring patient benefit from otorhinolaryngological surgery and therapy. Ann Otol Rhinol Laryngol 1996 Jun;105(6):415-422.

30. Kosowski TR, McCarthy C, Reavey PL, Scott AM, Wilkins EG, Cano SJ, Klassen AF, Carr N, Cordeiro PG, Pusic AL. A systematic review of patient-reported outcome measures after facial cosmetic surgery and/or nonsurgical facial rejuvenation. Plast Reconstr Surg 2009 Jun;123(6):1819-1827.

31. Hendry J, Chin A, Swan IR, Akeroyd MA, Browning GG. The Glasgow Benefit Inventory: a systematic review of the use and value of an otorhinolaryngological generic patient-recorded outcome measure. Clin Otolaryngol 2016 Jun;41(3):259-275.

32. Herruer JM, Prins JB, van Heerbeek N, Verhage-Damen GW, Ingels KJ. Negative predictors for satisfaction in patients seeking facial cosmetic surgery: a systematic review. Plast Reconstr Surg 2015 Jun;135(6):1596-1605.

33. Kotzampasakis D, Piniara A, Themelis S, Kotzampasakis S, Gabriel E, Maroudias N, Nikolopoulos T. Quality of life of patients who underwent aesthetic rhinoplasty: 100 cases assessed with the Glascow Benefit Inventory. Laryngoscope 2017 Sep;127(9):2017-2025.

34. Schwitzer JA, Klassen AF, Cano SJ, Baker SB, East C, Pusic AL. Measuring satisfaction with appearance: validation of the FACE-Q Scales for the nose, forehead, cheekbones, and chin. Plast Reconstr Surg 2015 Oct;136(4 Suppl):140-141.

35. Klassen AF, Cano SJ, Schwitzer JA, Scott AM, Pusic AL. FACE-Q scales for health-related quality of life, early life 
impact, satisfaction with outcomes, and decision to have treatment: development and validation. Plast Reconstr Surg 2015 Feb;135(2):375-386.

36. Klassen AF, Cano SJ, East CA, Baker SB, Badia L, Schwitzer JA, Pusic AL. Development and psychometric evaluation of the FACE-Q scales for patients undergoing rhinoplasty. JAMA Facial Plast Surg 2016 Jan-Feb;18(1):27-35.

37. Schwitzer JA, Albino FP, Mathis RK, Scott AM, Gamble L, Baker SB. Assessing demographic differences in patientperceived improvement in facial appearance and quality of life following rhinoplasty. Aesthet Surg J 2015 Sep;35(7): 784-793.

38. Schwitzer JA, Sher SR, Fan KL, Scott AM, Gamble L, Baker SB. Assessing patient-reported satisfaction with appearance and quality of life following rhinoplasty using the FACE-Q appraisal scales. Plast Reconstr Surg 2015 May;135(5):830e-837e.

39. Radulesco T, Mancini J, Penicaud M, Dessi P, Michel J. Assessing normal values for the FACE-Q rhinoplasty module: an observational study. Clin Otolaryngol 2018 Feb.

40. Golshani S, Mani A, Toubaei S, Farnia V, Sepehry AA, Alikhani M. Personality and psychological aspects of cosmetic surgery. Aesthetic Plast Surg 2016 Feb;40(1):38-47.

41. Baykal B, Erdim I, Ozbay I, Oghan F, Oncu F, Erdogdu Z, Kayhan FT. Evaluation of relationship between body dysmorphic disorder and self-esteem in rhinoplasty candidates. J Craniofac Surg 2015 Nov;26(8):2339-2341.

42. American Psychiatric Association. Somatoform disorders. Diagnostic and statistical manual of mental disorders: DSM-5. DSM-5 ed. Washington (DC): American Psychiatric Press Inc; 2013.

43. Goin MK, Rees TD. A prospective study of patients' psychological reactions to rhinoplasty. Ann Plast Surg 1991 Sep;27(3):210-215.

44. Atalay, B. Math and the Mona Lisa: the art and science of Leonardo da Vinci. New York: Haper Collins; 2006.

45. Lines PA, Lines RR, Lines CA. Profilemetrics and facial esthetics. Am J Orthod 1978 Jun;73(6):648-657.

46. Gunter, JP.; Rohrich, RJ.; Adams, WP. Dallas rhinoplasty: nasal surgery by the masters. St. Louis (MO): Quality Medical Publishing; 2002.

47. Powell, N.; Humphrey, B. Proportions of the aesthetic face. In: Byrd HS, Hobar PC, editors. Rhinoplasty: a practical guide. New York: Thieme-Stratton; 1984.

48. Zaidel DW, Cohen JA. The face, beauty, and symmetry: perceiving asymmetry in beautiful faces. Int J Neurosci 2005 Aug;115(8):1165-1173.

49. Chatrath P, De Cordova J, Nouraei SA, Ahmed J, Saleh HA. Objective assessment of facial asymmetry in rhinoplasty patients. Arch Facial Plast Surg 2007 May-Jun;9(3):184-187.
50. Nouraei SA, Pulido MA, Saleh HA. Impact of rhinoplasty on objective measurement and psychophysical appreciation of facial symmetry. Arch Facial Plast Surg 2009 May-Jun;11(3):198-202.

51. Fang F, Clapham PJ, Chung KC. A systematic review of interethnic variability in facial dimensions. Plast Reconstr Surg 2011 Feb;127(2):874-881.

52. Monheit, GD. Combination chemical peelings. In: Lowe NJ, editor. Textbook of facial rejuvenation: the art of minimally invasive combination therapy. London: Martin Dunitz; 2002.

53. Glogau RG, Matarasso SL. Chemical face peeling: patient and peeling agent selection. Facial Plast Surg 1995 Jan;11(1):1-8.

54. Aufricht G. Combined plastic surgery of the nose and chin; resume of twenty-seven years' experience. Am J Surg 1958 Feb;95(2):231-236.

55. Guyuron B, Raszewski RL. A critical comparison of osteoplastic and alloplastic augmentation genioplasty. Aesthetic Plast Surg 1990 Summer;14(3):199-206.

56. Farkas, LG. Anthropometry of the head and face. 2nd ed. New York: Raven Press; 1994.

57. Boahene, KD.; Orten, SS.; Hilger, PA. Facial analysis of the rhinoplasty patient. In: Papel ID, Frodel JL, Holt GR, Larrabee WF, Nachlas NE, Park SS, Sykes JM, Toriumi DM, editors. Facial plastic and reconstructive surgery. 3rd ed. New York: Thieme; 2009. pp. 477-487.

58. Tardy ME. Rhinoplasty tip ptosis: etiology and prevention. Laryngoscope 1973 Jun;83(6):923-929.

59. Sulsenti G, Palma P. Tailored nasal surgery for normalization of nasal resistance. Facial Plast Surg 1996 Oct;12(4):333-345.

60. Tardy, ME Jr.; Broen, M. Principles of photography in facial plastic surgery. New York: Thieme; 1992.

61. Bond, M.; Bell, A. The IMI National Guidelines for rhinoplasty and septorhinoplasty photography. London: IMI; 2006.

62. Tardy ME, Dayan S, Hecht D. Preoperative rhinoplasty: evaluation and analysis. Otolaryngol Clin North Am 2002 Feb;35(1):1-27.

63. Ozkul T, Ozkul MH. Computer simulation tool for rhinoplasty planning. Comput Biol Med 2004 Dec;34(8):697-718.

64. Ende KH, Lewis DL, Kabaker SS. Body dysmorphic disorder. Facial Plast Surg Clin North Am 2008 May;16(2):217-223.

65. Lekakis G, Claes P, Hamilton GS, Hellings PW. Threedimensional surface imaging and the continuous evolution of preoperative and postoperative assessment in rhinoplasty. Facial Plast Surg 2016 Feb;32(1):88-94.

66. Durer A. "Hierinn sind begriffen vier Bucher von menschlicher Proportion durch Albrechten Durer von Nurerberg". Hieronymus Andreae Formschneider. Available on https:/ / archive.org/details/hierinnsindbegri00dure/page/n3; accessed on 6 August 2018. 